\title{
VISI ARIF BUDIMAN DALAM ARUS KEDWIBAHASAAN DI SINGAPURA
}

\author{
The Vision of Arif Budiman towards Bilingualism in Singapore \\ Haslindah Mispan \\ haslindah_mispan@moe.gov.sg
}

Kementerian Pendidikan Singapura

\begin{abstract}
ABSTRAK
Dasar dwibahasa menjadi tunjang dalam sistem pendidikan di Singapura. Keupayaan menggunakan bahasa Inggeris (EL) membolehkan Singapura membina perhubungan dengan dunia. Menguasai bahasa ibunda pula menghubungkan warga dengan warisan dan jati diri budaya mereka. Untuk menjayakan dasar ini, kajian deskriptif telah dilakukan bagi memperhalus pengajaran dan pembelajaran (PdP) Bahasa Melayu (BM), bermula di sekolah rendah terutama dalam konteks penggunaan BM di rumah yang berubah. Melalui tinjauan, 37 peratus murid darjah 1 yang mengambil BM pada tahun 2010 datang daripada keluarga yang berbahasa Inggeris berbanding dengan 13 peratus pada tahun 1991. Hal ini mempengaruhi sikap terhadap pembelajaran Bahasa Melayu. Lantas matlamat kertas kerja ini membincangkan perubahan dan implikasi terhadap kandungan, pedagogi dan penilaian dalam PdP di sekolah rendah dalam usaha merealisasikan visi PdP BM, Arif Budiman, insan berilmu yang berbakti kepada masyarakat.
\end{abstract}

Kata kunci: dasar dwibahasa; Visi Arif Budiman; semakan kurikulum; pedagogi; penilaian

\begin{abstract}
The bilingual policy is a cornerstone of Singapore education system. The ability to use English Language (EL) enables Singaporean to connect with the world. The mother tongue languages are linked to the heritage and roots of the various ethnic groups. To ensure the success of this policy, a study was carried out to refine the teaching and learning of Malay Language (ML), especially in this changing language environment. From a survey, 37 percent of pupils entering primary 1 came from homes using English as a dominant language in 2010 compared to 13 percent in 1991. This has influenced the teaching and learning of ML. Hence, the aim of this paper is to discuss on the changes and implications on the content, pedagogy and assessment in the teaching and learning of $M L$ in primary schools so as to realise the vision of Arif Budiman, a learned person who contributes to the community.
\end{abstract}

Keywords: bilingual policy; Vision of Arif Budiman; curriculum; pedagogy and assessment review

\section{PENGENALAN}

Dwibahasa merupakan dasar penting dalam sistem pendidikan di Singapura. Sejak 1959, dasar dwibahasa ini telah dilaksanakan agar rakyat Singapura dapat menguasai bahasa Inggeris (EL) bagi kepentingan ekonomi dan mengekalkan nilai tradisi serta mengukuhkan jati diri melalui bahasa ibunda (Dixon, 2005). Selama lebih lima dekad, dasar ini mendapat banyak perhatian sama ada di dalam dan luar negara. Pelaksanaan dasar ini juga sering dipertikaikan dalam usaha mempertingkatkan mutu pendidikan bahasa, sekaligus mencapai hasrat dasar dwibahasa. Dalam masa yang sama, negara kecil dan muda ini mengalami perubahan demografi yang agak pesat. Perubahan ini juga telah mendesak agar pemerintah mengambil langkah meneliti dan meningkatkan mutu pelaksanaan dasar dwibahasa 
ini. Lantas, diadakan perdebatan dan perbincangan di pelbagai peringkat untuk mengemas kini kurikulum bahasa agar dapat menyelaraskan perubahan yang berlaku terhadap penggunaan bahasa dalam kalangan masyarakat majmuk di Singapura dengan pembelajaran dan pengajaran BM. Langkah ini bertujuan untuk memperbaiki dan memperkukuhkan pelaksanaan dasar bahasa ini dan menjadikan BM tetap relevan. Hal ini penting demi memastikan bahawa generasi muda berupaya untuk menghadapi tuntutan globalisasi pada masa ini dan hadapan (Laporan Jawatankuasa Semakan Kurikulum dan Pedagogi Bahasa Melayu 2005).

\section{LATAR BELAKANG DAN PERKEMBANGAN DASAR KEDWIBAHASAAN}

Dasar dwibahasa di Singapura mengharungi satu perjalanan cuba jaya yang banyak memberikan pengajaran yang tidak ternilai harganya (Lee K. Y., 2012). Bermula tahun 1959, dasar ini diperkenalkan di sekolah-sekolah rendah aliran Inggeris dengan Bahasa Inggeris (EL) sebagai Bahasa Pertama (L1) manakala Bahasa Mandarin (BC), Bahasa Melayu (BM) atau Bahasa Tamil (BT) sebagai Bahasa Ibunda (BI). Bagi sekolah-sekolah beraliran Melayu, Tamil dan Cina, bahasa yang ditawarkan sebagai bahasa kedua (L2) ialah EL. Namun, hasil pelaksanaan dasar dwibahasa tidak menampakkan kejayaan kerana para pelajar didapati hanya berjaya dalam bidang akademik dan sosial sahaja tanpa menguasai L2. Hal ini ditambah pula dengan kurangnya apresiasi pelajar dan ibu bapa tentang nilai tambah yang diperoleh daripada penguasaan lebih daripada satu bahasa dalam konteks kepelbagaian bangsa dan budaya di Singapura. Perkara ini dijelaskan dalam Laporan Suruhanjaya Siasatan dalam Pendidikan pada tahun 1963 yang dibentuk untuk menilai pengajaran dan pembelajaran bahasa ketika itu. Laporan itu juga menjelaskan bahawa sehingga kita tidak dapat menghargai dan menghayati nilai menguasai pelbagai bahasa dalam kehidupan, kita tidak dapat menguasai pelbagai bahasa (Lim, T.B. \& Commission of Inquiry into Education, 1964, hal. 26).

Di samping itu, terdapat juga saranan bagi menjelaskan cara-cara meningkatkan pengajaran dan pembelajaran (PdP) bahasa serta penekanan yang lebih terhadap aspek fungsional. Keutamaan diberikan kepada pembinaan asas bahasa yang kukuh. Selanjutnya pada tahun 1966, semua pelajar di peringkat Menengah 1 pula diwajibkan mengambil L2. Hal ini dikukuhkan lagi dengan Bahasa Kedua (L2) sebagai kertas wajib dalam Peperiksaan Sijil Am Pelajaran Peringkat Biasa (GCE ‘O’ Level) pada tahun 1969 pula (Lee, K. Y. 2012).

Penekanan yang sama dapat dilihat terhadap L1 dan L2 apabila pertimbangan dua kali ganda diberikan kepada kedua-dua bahasa ini dalam Peperiksaan Tamat Sekolah Rendah bermula pada tahun 1973. Pada tahun 1979 pula, pelajar-pelajar harus lulus sekurang-kurangnya D7 dalam kertas BI, peperiksaan peringkat biasa untuk meneruskan pelajaran di peringkat prauniversiti.

Pada tahun 1981, kriteria ini dilanjutkan untuk kemasukan ke universiti. Hal ini menunjukkan bahawa penekanan terhadap dasar dwibahasa adalah tekal dan berterusan untuk semua peringkat dalam sistem pendidikan. Walaupun terdapat penurunan dari segi kemasukan ke sekolah-sekolah vernakular dan peningkatan kemasukan ke sekolah beraliran Inggeris dalam tahun 80-an, keadaan ini tidak menjejaskan dasar dwibahasa. Hal ini berterusan sehinggalah sekolah-sekolah vernakular ditutup pada tahun 1987.

Di samping itu, terdapat juga usaha-usaha lain seperti menambah masa pendedahan untuk penggunaan L2 bagi murid-murid melalui mata pelajaran lain seperti Sivik dan Pendidikan Moral dan Matematik. Contohnya, terdapat sekolah menengah beraliran Melayu yang menawarkan mata pelajaran Sains dan Matemetik dalam EL. Hal ini merupakan satu lagi usaha bagi menyokong dan menggalakkan penggunaan L2 dalam kalangan pelajar. Walau bagaimanapun, beberapa kumpulan yang berkepentingan dalam pendidikan seperti pengetua, guru dan ibu bapa melahirkan keprihatinan mereka tentang langkah tersebut.

Usaha untuk meningkatkan lagi PdP bagi ketiga-tiga Bahasa Ibunda (BI), bahan-bahan pengajaran telah disediakan dengan terbentuknya Institut Pengembangan Kurikulum Singapura (CDIS) pada tahun 1986. Bahan-bahan yang dibina bagi memenuhi tuntutan kurikulum dalam meningkatkan penguasaan kemahiran bahasa dan kandungan bahasa serta panduan guru agar dapat menjalankan pengajaran dan pembelajaran yang berkesan di dalam kelas. 


\section{SEMAKAN DEMI SEMAKAN}

Dasar dwibahasa ini semakin menjadi lebih penting dan genting apabila terdapatnya perubahan demografi dalam penggunaan bahasa yang lebih dominan di rumah dalam kalangan masyarakat Singapura. Antara tahun 1990 hingga tahun 2015 ini, Kurikulum Bahasa Ibunda telah mengalami empat semakan dan hal ini bertujuan untuk meningkatkan mutu PdP bagi memperbaik penguasaan BI dalam kalangan masyarakat Singapura. Semakan BI yang dijalankan dalam tahun 1992 dipengerusikan oleh Timbalan Perdana Menteri ketika itu, Encik Ong Teng Cheong.

Hasil semakan mendapati bahawa sistem penyaluran dalam peringkat sekolah rendah telah diperhalus dan bermula dari darjah lima untuk menduduki Peperiksaan Tamat Sekolah Rendah pada peringkat darjah enam kepada tiga saluran; EM1 menawarkan BI dan BM di peringkat L1, EM2 menawarkan BI di peringkat L1 dan BM di peringkat L2 dan EM3 menawarkan BI di peringkat dasar dan kecekapan asas dalam BM. Penyaluran ini berterusan ke peringkat sekolah menengah. Kursus Bahasa Melayu yang bersesuaian ditawarkan kepada para pelajar mengikut pencapaian dan penguasaan bahasa mereka. Bahan pengajaran juga dibangunkan bersesuaian dengan aliran atau kursus bahasa yang disalurkan. Penyaluran ini berdasarkan keputusan yang diperoleh dari peperiksaan utama pada peringkat kebangsaan.

Semakan Bahasa pada tahun 1999 dipengerusikan oleh Timbalan Perdana Menteri ketika itu, Encik Lee Hsien Loong. Semakan yang melibatkan tinjauan terhadap kira-kira 1000 orang pelajar menunjukkan bahawa pelajar meluangkan lebih banyak masa untuk mempelajari BI berbanding dengan mata pelajaran lain seperti EL dan matematik. Komen yang serupa juga diberikan oleh guru dan ibu bapa dalam sesi perbincangan fokus bersama dua golongan yang berkepentingan ini.

Hasil daripada semakan ini, sebagai satu lagi pilihan bagi pelajar yang menghadapi kesukaran dalam menguasai BI, Sukatan Bahasa Ibunda B (Sukatan B) diperkenalkan. Sukatan ini mempunyai kandungan dan teks yang lebih mudah dan perbendaharaan kata yang lebih kecil. Hanya pelajar yang memperoleh gred $\mathrm{C}$ ke bawah dan menghadapi kesukaran menguasai BI dibenarkan untuk menawarkan sukatan ini. Pengajaran bahasa dalam sukatan ini lebih berfokus kepada kemahiran mendengar dan bertutur, dan sukatan ini bukan merupakan pilihan bagi pelajar yang berupaya menguasai bahasa ibunda. Walau bagaimanapun, ada juga yang menjadikan sukatan ini sebagai pilihan bukan kerana ketidakupayaan. Mereka merupakan golongan yang menjadikannya sebagai jalan mudah untuk lolos daripada mengambil BM sebagai BI. Oleh itu, sekolah diberi autonomi untuk membenarkan murid yang hanya layak menawarkan sukatan ini.

Bagi melaksanakan saranan Jawatankuasa Semakan Bahasa 1999, usaha-usaha lain yang berkaitan dengan pengajaran dan pembelajaran bahasa terus dijalankan. Pemantauan juga dilakukan terhadap pelaksanaan kurikulum bahasa terutama sekali dari segi PdP di samping meneliti trend perubahan persekitaran bahasa pada tempoh lebih daripada 20 tahun. Bahan-bahan pengajaran yang baharu disediakan untuk keperluan pelajar-pelajar ini.

\section{PERUBAHAN TREND PENGGUNAAN BAHASA DI SINGAPURA}

Kementerian Pendidikan (MOE) telah membentuk Jawatankuasa Semakan Kurikulum dan Pedagogi Bahasa Melayu (MLCPRC) pada tahun 2005 untuk memperbaiki PdP BM pada setiap peringkat. Semakan ini dipacu oleh keinginan untuk memastikan agar bahasa dan budaya Melayu dapat dikekalkan dan berkembang serta kukuh dalam menyokong dasar dwibahasa. Pihak MOE berharap agar semakan yang dijalankan ini berkesan dan dapat memperkukuh jati diri masyarakat Melayu dalam konteks Singapura sebagai sebuah masyarakat Asia. Dalam usaha penyemakan, perbincangan fokus, sesi dialog dan wawancara dengan pihak yang mempunyai kepentingan dalam bidang pendidikan seperti pengetua sekolah, guru, pelajar, ibu bapa, pensyarah institut pengajian tinggi dan wakil-wakil pertubuhan Melayu. Terdapat juga lawatan ke atas enam buah sekolah di Singapura dan lawatan sambil belajar ke Malaysia yang bertujuan untuk meneliti aspek-aspek pengajaran, pembelajaran dan penilaian dalam pelaksanaan Kurikulum BM. 
Hasil dapatan daripada tinjauan yang dijalankan oleh MOE pada tahun 2004 terhadap 7500 responden yang terdiri daripada guru, pelajar dan ibu bapa terdapat kemerosotan yang perlahan-lahan, tetap dan tekal bagi pelajar yang menggunakan BM sebagai bahasa yang lebih dominan di rumah daripada 82 peratus pada tahun 1996 kepada 71 peratus pada tahun 2005. Hal ini bererti dalam masa sembilan tahun terdapat penurunan sebanyak 11 peratus keluarga yang tidak lagi menggunakan BM di rumah. Selain itu, pelajar yang datang dari keluarga yang menggunakan EL menghadapi kesukaran mempelajari BM dan tidak suka membaca buku Melayu. Mereka cepat berasa bosan mempelajari BM kerana tidak begitu memahami BM. Walau bagaimanapun, golongan ini membentuk lebih kurang 10 peratus pelajar BM, sedangkan 90 peratus yang lain masih bersikap positif terhadap pembelajaran BM dan suka mempelajari BM terutama dalam kalangan pelajar muda dan peratusan ini merosot ke paras 88 peratus dalam kalangan pelajar dewasa.

\section{VISI ARIF BUDIMAN}

Setelah meneliti dan memahami maklumat yang diperoleh, Jawatankuasa menyarankan agar PdP BM harus berpandukan Visi Arif Budiman yang bermaksud insan yang berilmu pengetahuan yang berbakti kepada masyarakat. Visi Arif Budiman ini diharapkan dapat menggerakkan guru dan pelajar BM ke satu arah yang boleh mempertingkatkan kemahiran berbahasa dan penghayatan budaya Melayu. Visi ini disokong oleh tiga matlamat pembelajaran BM; semangat untuk cemerlang, cekap bertutur dan pembelajaran pembezaan.

Berdasarkan Visi ini dan ketiga-tiga matlamat tersebut, Sukatan Pelajaran BM Sekolah Rendah 2008 dibina agar dapat menterjemahkan hasrat murni ini dalam bentuk tindakan dalam PdP BM di dalam dan di luar kelas. Segala peluang dan ruang yang disediakan untuk menggalakkan pelajar mempelajari BM sejauh mana yang mungkin dan setinggi mana yang termampu terus ditingkatkan. Terdapat juga penekanan terhadap pengajaran pembezaan yang mengambil kira latar belakang, kebolehan dan minat pelajar yang berbeza. Pengajaran pembezaan ini diserlahkan dalam sukatan pelajaran dan bahan pengajaran yang baharu. Program membaca juga dikukuhkan dan teknologi maklumat digunakan sebagai alat yang dapat membantu pengajaran dan menarik minat pelajar terhadap BM.

Jawatankuasa ini juga mengakui bahawa penglibatan ibu bapa dan masyarakat umum dalam membina suasana budaya dan bahasa Melayu amat penting dalam menyokong pengajaran dan pembelajaran BM. Peratusan yang tinggi menunjukkan bahawa ibu bapa masih menganggap BM penting dalam mengukuhkan jati diri pelajar. Oleh yang demikian, Jawatankuasa Pembelajaran dan Penggalakan Penggunaan Bahasa Melayu (MLLPC) ditubuhkan untuk menggabungkan sokongan pertubuhan masyarakat bagi menggalakkan pembelajaran dan penggunaan BM di luar bilik darjah. MLLPC berperanan untuk menyelaras dan menggalakkan kegiatan BM dalam kalangan pertubuhan Melayu, media, sekolah dan institusi pengajian tinggi dalam bentuk peruntukan dana. Kegiatan ini dipantau untuk memastikan keberkesanannya dalam menggalakkan penggunaan BM.

Segala usaha pelaksanaan saranan yang dikemukan oleh MLCPRC dipantau dengan teliti. Pada masa yang sama, MOE juga meluaskan jangkauan pemerhatian terhadap segala perubahan persekitan bahasa di dalam negara dan perkembangan pengajaran dan pembelajaran bahasa yang berlaku di pelosok dunia. Ini jelas menunjukkan bahawa terdapat komitmen MOE yang kukuh dalam memastikan bahawa mutu pengajaran dan pembelajaran bahasa akan terus ditingkatkan dan segala tindakan yang dilakukan haruslah berasaskan pertimbangan yang saksama. Atas sebab inilah satu lagi semakan telah dilakukan pada tahun 2010 .

\section{MEMUPUK PELAJAR AKTIF DAN PENGGUNA CEKAP}

Semakan ini perlu dilakukan untuk mengemas kini dan memperhalus pendidikan Bahasa Ibunda agar sentiasa mengikuti perubahan persekitaran bahasa yang berlaku di Singapura dan seluruh dunia. Jawatankuasa telah mengadakan lawatan sambil belajar ke Amerika Syarikat, Australia, China, India dan Malaysia untuk mempelajari pengalaman dan perkembangan pendidikan bahasa di negara-negara 
ini. Kebanyakan negara-negara ini tidak menghadapi situasi yang serupa dengan apa yang terdapat di Singapura. Namun, negara-negara ini juga melabur untuk meningkatkan PdP bahasa.

Selain itu, semakan kali ini melibatkan lebih ramai pelajar, guru, ibu bapa, pemimpin masyarakat, institut pengajian tinggi untuk meneliti PdP bahasa di Singapura (Laporan Jawatankuasa Semakan Bahasa Ibunda 2010). Tinjauan dan perbincangan dengan pihak-pihak berkepentingan menunjukkan bahawa pelaksanaan semakan 2005 telah memberikan manfaat kepada pendidikan BI. Peratusan murid yang meminati BM semakin meningkat. Ibu bapa dan guru mengesahkan bahawa inisiatif yang dilaksanakan dalam kurikulum berasaskan semakan 2005 seperti penekanan terhadap kemahiran mendengar dan bertutur, pengajaran pembezaan, penggunaan teknologi maklumat, bahan pengajaran yang menekankan pelibatan pelajar dan program bacaan membuahkan hasil yang positif. Ibu bapa juga mengiktiraf usaha gigih guru dalam melaksanakan perubahan tersebut. Guru-guru telah melibatkan diri secara aktif untuk memperbaiki pengajaran dan pembelajaran bahasa dengan mengikuti kursus, bengkel dan perkongsian profesional yang diadakan di dalam dan luar negara.

Hasil dapatan positif ini memberikan satu pengesahan bahawa pembaharuan yang dilakukan sesuai dan di bawah landasan yang betul. Pada masa yang sama, tinjauan yang dilakukan terhadap 22,000 orang guru, pelajar dan ibu bapa memperlihatkan anjakan penggunaan bahasa ibunda yang tekal dalam dua dekad terakhir ini. Data yang dikumpulkan ini telah membuktikan bahawa semakin ramai keluarga menggunakan EL di rumah dan peratusan ini dijangkakan akan meningkat. Rajah yang berikut menunjukkan peratusan bahasa pertuturan murid darjah 1 di rumah pada sepanjang 20 tahun (Laporan Jawatankuasa Semakan Bahasa, 2010).
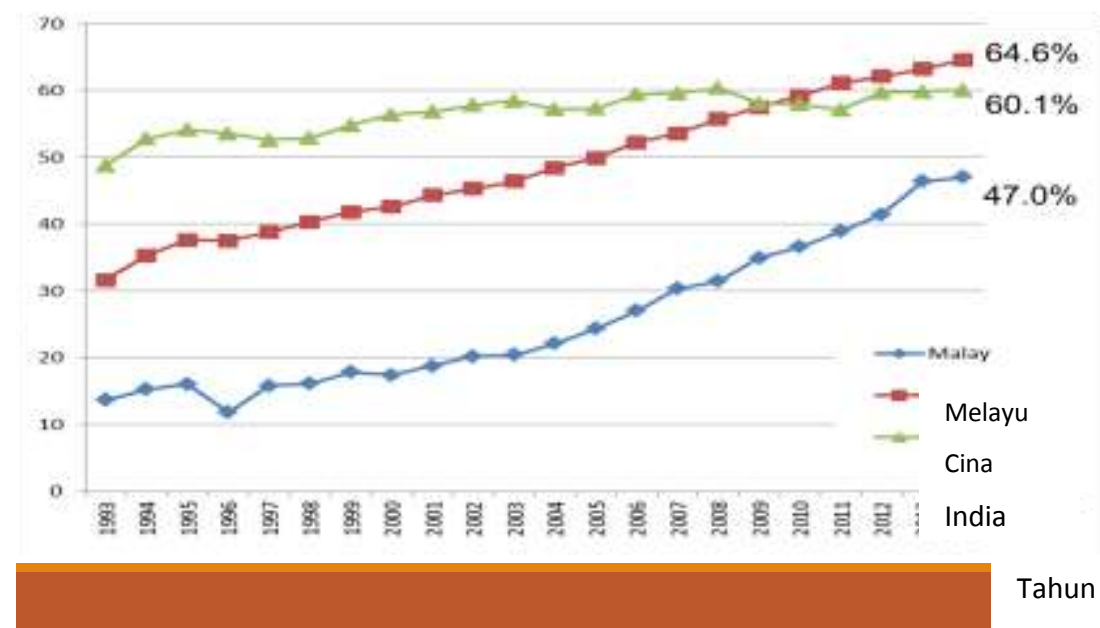

RAJAH 1 Peratusan Darjah 1 dengan Bahasa Inggeris di Rumah (Sumber: Laporan Jawatankuasa Semakan Bahasa Ibunda, 2010)

Satu perkara yang dipaparkan ialah terdapat peningkatan daripada 13 peratus dalam tahun 1993 kepada 37 peratus dalam tahun 2010 dan peraturan ini masih meningkat setiap tahun selepas itu. Terdapat juga kenaikan dalam penggunaan bahasa Inggeris (17 peratus) dan dwibahasa (33 peratus) dalam kalangan murid-murid darjah 6 kepada 50 peratus. Sebanyak 50 peratus lagi menggunakan BM di rumah dan tidak dapat disangkal bahawa peratusan ini semakin menurun setiap tahun.

Peningkatan peratusan penggunaan EL sebagai bahasa dominan di rumah dalam kalangan murid merupakan satu kenyataan yang harus diterima. Seperti yang telah dilaporkan dalam Laporan MLCPRC 2005, keadaan ini menyukarkan kanak-kanak mempelajari BM dan menggunakannya sebagai bahasa harian dalam kehidupan. Realitinya ialah lebih ramai murid yang masuk ke sekolah dengan berbekalkan asas bahasa ibunda yang terhad atau tidak mempunyai asas bahasa langsung. Mereka mula mempersoalkan nilai mempelajari BM. Hal ini ditambah pula dengan profil pelajar yang 
semakin rencam melalui perkahwinan campur yang menyukarkan lagi pengkelasan bahasa ibunda mereka yang 'tepat'.

\section{IMPLIKASI TERHADAP KURIKULUM, PEDAGOGI DAN PENILAIAN}

Memahami perubahan-perubahan ini dan berbekalkan pelaksanaan kurikulum yang dilakukan berdasarkan semakan 2005, usaha perlu diteruskan untuk memperhalus pengajaran dan pembelajaran BM. Jawatankuasa 2010 menekankan peri pentingnya menjadikan bahasa ibunda bahasa yang hidup agar dapat digunakan dan dihargai - lebih daripada menjadi satu subjek peperiksaan. Segala usaha memupuk persekitaran yang lebih kondusif untuk menggalakkan penggunaan dan pembelajaran bahasa disokong oleh MOE. Pihak sekolah digalakkan bergabung tenaga dengan masyarakat umum untuk menganjurkan Dwiminggu Bahasa Ibunda yang dapat menarik minat dan pelibatan murid serta menambah persekitaran pembelajaran bahasa yang hanya terhad di sekolah. Peranan MLLPC juga dipertingkatkan dengan menambah dana bagi menyelaraskan kegiatan-kegiatan masyarakat demi menyemarakkan penggunaan BM.

Dalam usaha meningkatkan pengajaran dan pembelajaran, kurikulum dikemas kini agar dapat memupuk pelajar yang aktif, pengguna bahasa yang cekap. Satu hal yang penting adalah dengan mengambil kira latar belakang dan kebolehan murid yang pelbagai. Oleh itu, pendekatan pembelajaran pembezaan haruslah diteruskan dan diperluas untuk memenuhi keperluan murid. Dalam hal ini, MOE telah membina deskriptor kecekapan atau garis pandu kecekapan bahasa yang ingin dicapai pada peringkat-peringkat tertentu. Deskriptor ini juga dirujuk untuk menyelaraskan antara pengajaran dan penilaian selain dijadikan panduan semasa pembinaan bahan pengajaran. Proses PdP BM seharusnya menjadi lebih bersifat interaktif dan melibatkan pelajar agar penggunaan bahasa menjadi lebih relevan dalam kehidupan mereka. Hal ini ditekankan dalam Sukatan Pelajaran BM 2015. Terdapat juga usaha meningkatkan penggunaan lebih banyak alat informasi dan komunikasi agar dapat memberikan kesempatan bagi mempelajari BM demi menarik minat pelajar belajar BM.

\section{BAHAN PENGAJARAN CEKAP}

Bahan pengajaran seperti 'Buku Teks', 'Buku Aktiviti' dan 'Panduan Guru' telah dibina untuk menerapkan deskriptor kecekapan bagi memandu pengajaran dan pembelajaran. Bahan-bahan lain yang menyokong juga dibina seperti 'Buku Besar', 'Buku Kecil', 'Kit Permainan', 'Kad Imbasan', 'Kad Bergambar' dan bahan-bahan ICT dalam bentuk talian dibina untuk menyediakan suasana pembelajaran yang kaya dengan pelbagai sumber dalam pelbagai bentuk bagi memenuhi keperluan murid daripada pelbagai tahap kecerdasan. Bagi memastikan mutu bahan agar terpelihara, pembangunan bahan ini telah melibatkan penelitian daripada pelbagai golongan di pelbagai peringkat termasuklah guru, ketua jabatan, pengetua, pensyarah dan perunding cara yang akan meneliti kandungan, pedagogi dan penilaian agar selaras dengan hasrat Sukatan Pelajaran BM Sekolah Rendah 2015. Bersesuaian dengan matlamat membina kecekapan bahasa pelajar-pelajar, pakej pengajaran BM dinamakan Pakej CEKAP.

Yang berikut merupakan bahan-bahan yang bercetak yang diterbitkan oleh MOE bagi kegunaan guru dan murid dalam pembelajaran. Bahan-bahan tersebut terdiri daripada buku teks, buku aktiviti, panduan guru, kad bergambar, kad imbasan, buku kecil dan buku besar. Kit permainan bahasa juga dicetak untuk membantu guru menjadikan PdP menyeronokkan. 


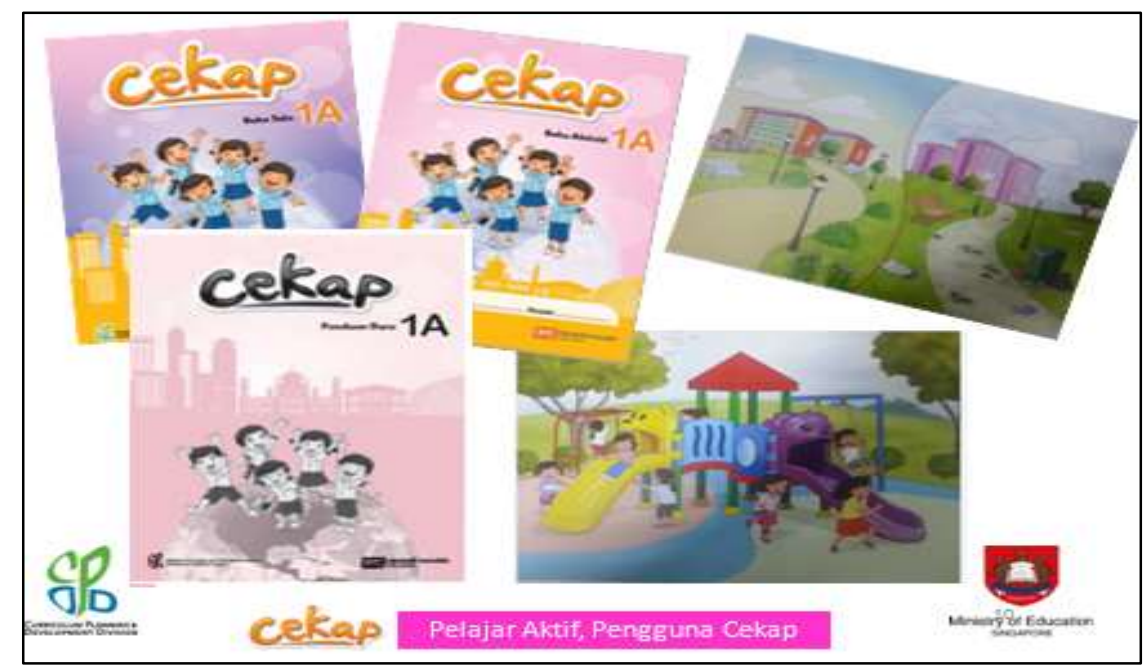

GAMBAR 1 Bahan Bercetak: Buku Teks, Buku Aktiviti, Panduan Guru dan Kad Bergambar

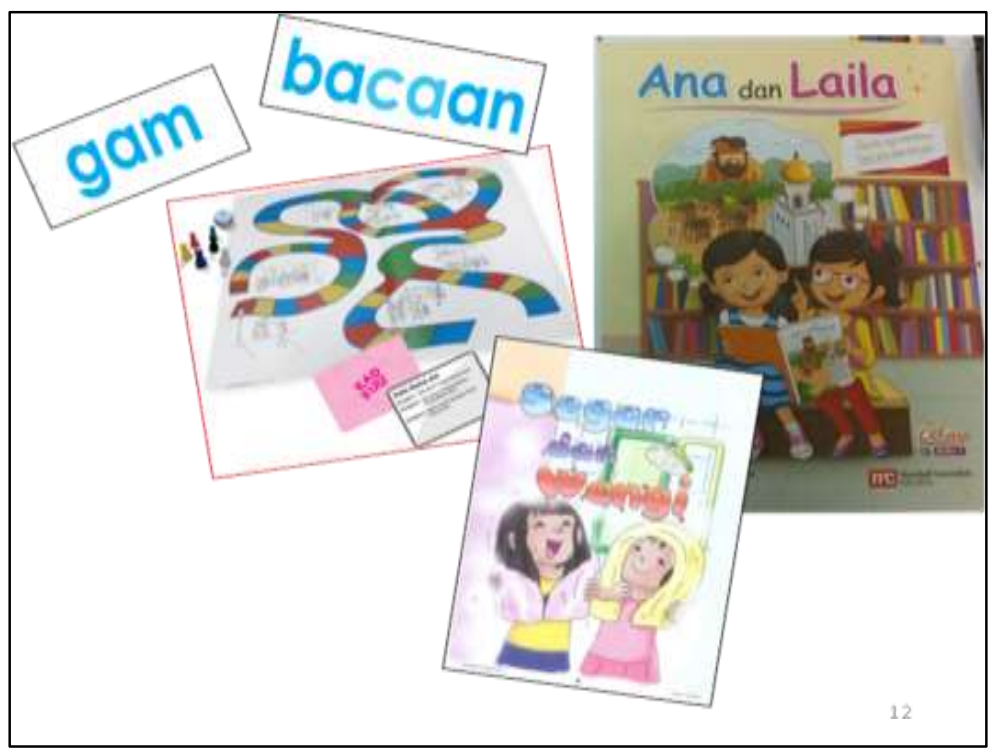

GAMBAR 2 Bahan Bukan Bercetak: Buku Besar, Buku Kecil, Kad Imbasan dan Kit Permainan

Portal e-Cekap pula dibina untuk memuatkan bahan-bahan sokongan berbentuk elektronik. Bahan-bahan audio seperti lagu, cerita naratif dan kefahaman mendengar ini disediakan selaras dengan tajuk yang terdapat dalam unit-unit tertentu dan tuntutan kemahiran mendengar dan bertutur yang terdapat dalam sukatan pelajaran BM di sekolah rendah. Di samping itu, terdapat juga bahan video yang diharap dapat menarik minat murid sekaligus mempelajari bahasa dengan lebih mudah. Bahan ini terdapat dalam contoh paparan yang berikut. 


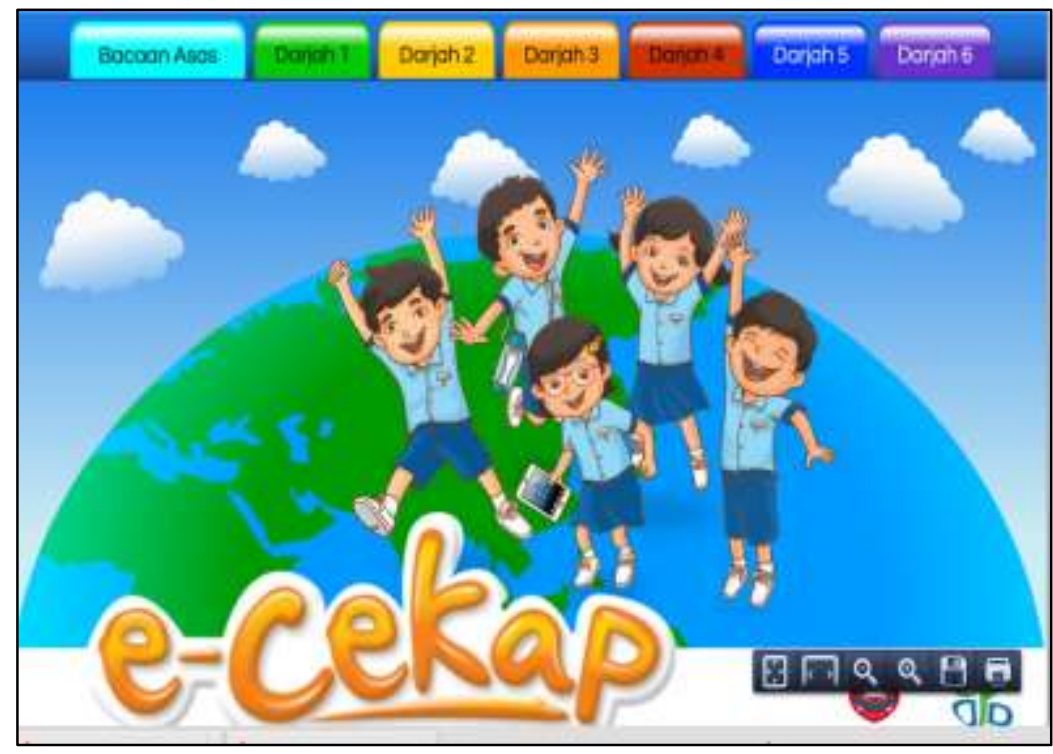

GAMBAR 3 Portal E-Cekap

Pakej ini juga menyediakan bahan bagi memenuhi keperluan murid yang mempunyai kebolehan dan minat yang berbeza. Bahan-bahannya termasuklah bahan-bahan pengayaan untuk murid yang berkebolehan dalam bahasa dan bahan titian untuk mereka yang memerlukan sokongan tambahan dalam proses penguasaan bahasa. Dalam pada itu, penerapan dan penyerapan nilai disertakan untuk memenuhi matlamat pendidikan bahasa iaitu meneguhkan ikatan budaya dan mengukuhkan jati diri. Visi Arif Budiman masih relevan dalam usaha membentuk pelajar berkeyakinan yang berarah kendiri, masyarakat yang ambil dan menyumbang kepada bangsa dan negara. Hal ini selaras dengan falsafah pendidikan yang menjelaskan Hasil Pelajaran yang Diingini (Desired Learning Outcome) dalam dokumen Sukatan Pelajaran BM Sekolah Rendah 2015.

Dalam memastikan keberkesanan penggunaan bahan, guru-guru dilatih untuk menjalankan pengajaran dan pembelajaran BM bermula pada tahun 2014, setahun sebelum sukatan pelajaran yang baharu dilaksanakan. Terdapat juga kolaborasi antara guru dan pegawai MOE dalam usaha mempraktikkan pelbagai strategi dan teknik pengajaran untuk membantu pembelajaran murid. Guruguru juga diberikan peluang untuk berkongsi pengalaman dalam menjalankan pengajaran yang berkesan bagi meningkatkan profesionalisme mereka.

\section{MEMBINA BAHASA MELAYU DENGAN DWIBAHASA}

Walaupun demikian, belum ada usaha yang benar-benar konkrit yang digunakan untuk mengajarkan BM kepada murid-murid yang mempunyai latar belakang yang kukuh dalam EL. Guru masih ingin mengetahui strategi terkini yang lebih berkesan untuk menjadikan pengajaran dan pembelajaran Bahasa menyeronokkan. Mereka juga memerlukan sokongan untuk mendapatkan bahan pengajaran lain yang sesuai dan dapat membantu mereka meluaskan perbendaharan kata murid-murid yang mempunyai lebih keupayaan dalam bahasa Inggeris. Guru cuba menggunakan teknik terjemahan semasa pengajaran dijalankan untuk memudahkan pengajaran. Namun teknik ini didapati menjemukan dan tidak dapat menarik minat murid.

Sebenarnya, hal ini telah disarankan oleh Encik Lee Kuan Yew, Mantan Perdana Menteri, dalam mengajarkan BC dengan cara yang lebih efektif dan dapat membantu pembinaan dan pengukuhan dalam pembelajaran Bahasa. Beliau berpendapat bahawa:

"... If you are speaking English at home and you are taught Mandarin in Primary 1 by Chinese teachers who teach Mandarin as it was taught in the former Chinese schools, by 
the direct method, using only Mandarin, you will soon lose interest because you do not understand what the teacher is saying.

(Au Yong, the Straits Times, Home Page B6)

Oleh yang demikian, terdapat usaha dalam bentuk kajian tindakan yang ingin mengetahui sejauh mana berkesanya menggunakan bahan dwibahasa, BM dan EL dalam meluaskan perbendaharaan kata dan memudahkan pemahaman murid semasa mempelajari BM. Bahan ini digunakan dalam kegiatan membaca bersama yang dapat membentuk perkembangan literasi, memberikan kesan terhadap kemahiran bertutur seperti pemerolehan kosa kata dan kesedaran fonologi (Senechal \& Lefevre, 2002, hal. 445-460). Di samping itu, kajian ini membolehkan penelitian terhadap aspek lain seperti respons murid secara lisan dan interaksi bersama guru dan rakan-rakan mereka.

\section{BAHAN DWIBAHASA}

Bahan pengajaran dwibahasa (BM dan EL) dalam kajian ini ialah bahan yang mencetak dua bahasa pada satu halaman yang sama. BM dan EL menceritakan illustrasi pada halaman tersebut agar murid dapat memahami cerita yang disampaikan dalam BM dengan bantuan EL yang boleh dibaca oleh murid (Driessen, Westhoff, Haenen \& Brekelmans, 2008). Di sini, kemasukan atau bantuan BI disisipkan secara kontektual seperti yang disarankan oleh Krashen (1981). Selain mengenalkan golongan kata BM, buku ini juga merangsang penggunaan mental dan psikomotor dengan perkataan berima dan aktiviti membaca lantang. Menurut Krashen lagi, buku dwibahasa dapat meningkatkan keupayaan berdwibahsa agar murid teransang untuk membaca dalam kedua-dua bahasa sasaran, yakni BM dan EL.

\section{KERANGKA TEORI DAN KAJIAN LEPAS}

Penggunaan buku cerita dwibahasa mempertingkatkan pengajaran dwibahasa pernah dikaji oleh ramai pengkaji di barat termasuklah Durgunoglu et al., (1993 hal. 453-465) yang mengkaji faktor yang mempengaruhi penguasaan kosa kata EL bagi pembaca berbahasa Sepanyol. Mereka mendapati bahawa pencapaian mereka berkaitan dengan kebolehan mereka mengalihkan pengetahuan bahasa Sepanyol ke EL. Mereka juga membuat kesimpulan bahawa perkembangan fonologi EL bagi penutur bahasa Sepanyol ialah rentetan bukan serentak. Kajian Neugebauer dan Currie-Rubbin (2009) juga menunjukkan kesan positifpenggunaan buku dwibahasa Sepanyol dan EL dalam pengajaran bacaan di Calca, Peru. Hasil dapatan kajian tersebut menunjukkan bahawa penggunaan bahasa pertama untuk pembelajaran bahasa kedua telah menunjukkan keberkesanan dalam mengembangkan kosa kata dan pemahaman kanak-kanak.

Sneddon (2000) juga menggunakan buku dwibahasa, Albania dan EL, dalam buku cerita dua kanak-kanak tahun satu yang berketurunan Albania dan belajar di England. Kajian yang berlandaskan kerangka teori Cummins (1986) menunjukkan bahawa kejayaan dalam pendidikan boleh diraih jika bahasa dan budaya sesuatu masyarakat itu disepadukan dalam pengajaran. Cummins menggalakkan keluarga agar turut serta memainkan peranan yangaktif dalam pendidikan anak-anak mereka. Sekolah dan rumah harus menggalakkan sesi interaktif sewaktu pengajaran dan pembelajaran. Kajian Edwards, Monaghan \& Knight (2000) juga telah membuktikan bahawa penggunaan buku dwibahasa berkesan hasil daripada interaksi antara kanak-kanak dengan bahan dwibahasa tersebut. Dua bahasa yang terdapat dalam buku cerita ini telah mempercepatkan proses membina makna dan memberikan pemahaman kepada kanak-kanak pada teks yang dibaca.

Terdapat juga kajian dijalankan di Singapura baru-baru ini untuk mengesan penggunaan bahasa Melayu dalam meningkatkan pembelajaran Bahasa Inggeris (Vaish \& Subhan, 2014). Kajian yang bertajuk, "Translanguaging in a Reading Class" ini menyatakan bahawa bahasa Melayu yang digunakan sebagai perancah dapat meningkatkan 'masa pertuturan' pelajar dalam bahasa Inggeris. Pelajar juga berupaya menjawab soalan yang lebih kompleks mengenai teks berbanding dengan keadaan kelas yang menghadkan penggunaan bahasa Inggeris sahaja. Kajian Mukhlis dan Pang, (2015) 
mendapati bahawa penggunaan buku dwibahasa (BM dan EL) dalam membina literasi awal di rumah dapat membantu meningkatkan penguasaan dwibahasa kanak-kanak.

Oleh itu, satu kajian perlu dijalankan dalam kelas untuk mengetahui sejauh mana bahan dwibahasa (BM dan EL) dapat membantu pemerolehan bahasa Melayu dalam kalangan murid darjah 1 yang tidak terdedah dengan bahasa Melayu di luar kelas Bahasa Melayu. Kajian ini berlandaskan Teori Pemerolehan Bahasa Kedua (L2) oleh J. Cummins (1980). Menurut Cummins, penutur asing telah mempunyai kecekapan bertutur dalam bahasa pertama (L1) mereka dan hal ini dapat digunakan untuk mempelajari bahasa kedua (L2). Secara amnya, Cummins berpendapat bahawa dalam mempelajari bahasa, seorang pelajar memerlukan set kemahiran dan pengetahuan metalinguistik dalaman yang boleh digunakan semasa mempelajari bahasa lain. Hal ini dikenali sebagai Kecekapan Asas Umum yang menjadi dasar bagi pembelajaran bahasa kedua. Sebarang pengembangan dalam kecekapan umum ini akan memberikan kesan yang positif pada bahasa yang lain. Selain itu, tanda paralinguistik seperti pergerakan badan, intonasi suara dan mimik muka dapat digunakan untuk membina makna. Krashen (1981) juga menyatakan bahawa dalam memperolehan L1 atau L2, makna yang disampaikan aspek yang penting.

\section{KEPENTINGAN KAJIAN}

Kajian ini diharapkan dapat membantu murid membina pemahaman mereka semasa membaca lantang. Mereka akan terangsang untuk membaca. Guru tidak perlu terus menterjemah kerana murid boleh mendapat makna daripada teks EL. Dengan mengetahui apa yang dipelajari, keyakinan dan minat mereka untuk mempelajari BM dapat ditingkatkan. Guru mempunyai lebih masa untuk membina dan mengembangkan makna kosa kata yang terdapat dalam teks BM.

\section{KAEDAH KAJIAN}

Pengkaji menggunakan kaedah kuantitatif dan kualitatif untuk memperoleh data dan maklumat bagi menjalankan kajian yang berbentuk deskriptif ini. Terdapat juga kesedaran tentang batasan-batasan seperti tenaga dan kepakaran guru dalam menggunakan bahan dwibahasa ini. Untuk mengatasinya, latihan diberikan kepada guru-guru yang terlibat bagi memastikan keselarasan penyampaian.

Kaedah kuantitatif ini bertujuan untuk mendapatkan maklumat mengenai perbezaan pemerolehan kosa kata dan pemahaman murid dalam dua ujian; praujian yang dijalankan sebelum mengajar dan pascaujian yang dijalankan selepas mengajar. Data ini kemudiannya dikumpul dan dianalisis untuk memberikan informasi tentang pencapaian murid secara sendirian dan kumpulan. Bagi menyokong dan memastikan kesahan dapatan ini, kaedah kualitatif juga digunakan untuk mengumpulkan data. Pengumpulan data ini dijalankan dengan mencatatkan data anekdot, membuat pencerapan di dalam kelas dan bertemu ramah 2 orang guru dan 21 orang murid untuk memahami apa yang berlaku dalam kelas. Temu bual dijalankan selepas pencerapan dengan berpandukan soalan-soalan yang telah disediakan.

Kajian ini dijalankan di dua buah sekolah; Sekolah A, sekolah bantuan di Zon Selatan dan Sekolah B, sekolah pemerintah di Zon Timur. Pemilihan ini mengambil kira perkara-perkara yang berikut seperti yang digariskan oleh Marshall dan Rossman (1999):

- Sekolah-sekolah ini mempunyai murid BM yang datang daripada pelbagai latar belakang bahasa utama. Kedua-dua sekolah ini berkemungkinan besar dapat digunakan untuk melaksanakan pengumpulan data yang lebih seimbang.

- Kajian harus dapat diterima dan disokong oleh pihak sekolah terutama sekali daripada guru besar dan guru yang mengajar.

- Wujudnya hubungan yang baik dan kepercayaan antara guru dan pengkaji.

Sampel terdiri daripada 21 orang murid pelbagai bangsa; Cina, Filipino, India, Inggeris dan Serani. Mereka merupakan murid-murid yang datang dari keluarga yang tidak menggunakan BM di rumah. Terdapat juga beberapa orang murid Melayu yang memahami BM tetapi tidak boleh bertutur 
dengan lancar kerana ibu bapa menggunakan EL di rumah dan hanya terdedah dengan ahli keluarga yang tinggal berasingan seperti datuk dan nenek.

Kajian dijalankan mengambil masa lebih kurang dua bulan yang merangkumi temubual dengan guru, praujian dan pascaujian, pengajaran dengan menggunakan bahan dwibahasa dan wawancara dengan murid. Beberapa ujian statistik digunakan untuk mengetahui terdapatnya perubahan yang signifikan terhadap pencapaian murid.

\section{DAPATAN KAJIAN}

Hasil dapatan kuantitatif menunjukkan terdapat perubahan signifikan dalam tingkah laku murid menguasai kosa kata dan pemahaman selepas menggunakan buku dwibahasa ini. Min meningkat daripada 0.47 semasa praujian kepada 0.66 semasa pascaujian. Sisihan piawai juga semakin kecil daripada 0.27 ke 0.2 .

JADUAL 1 Taburan bagi Praujian dan Pascaujian

\begin{tabular}{|l|r|r|}
\hline & \multicolumn{1}{|c|}{ Praujian } & \multicolumn{1}{c|}{ Pascaujian } \\
\hline Jumlah & 21 & 21 \\
\hline Min & 46.86 & 66.10 \\
\hline Median & 40.00 & 67.00 \\
\hline Sisihan piawai & 26.598 & 20.393 \\
\hline Kelencongan & .620 & -.305 \\
\hline Jarak & 100 & 75 \\
\hline
\end{tabular}

Apabila diterjemahkan dalam bentuk graf yang berikut, kita dapat melihat bahawa jarak antara markah tertinggi dan markah terendah juga semakin kecil. Kedua-dua graf ini menunjukkan bahawa, penggunaan bahan dwibahasa dapat membantu pemerolehan dan meningkatkan kefahaman muridmurid secara kumpulan. Taburan markah semasa pascaujian menunjukkan terdapatnya dua puncak. Hal ini menjelaskan lagi perihal peningkatan secara perseorangan dan secara kumpulan selepas murid melalui proses pembelajaran dengan menggunakan bahan dwibahasa.

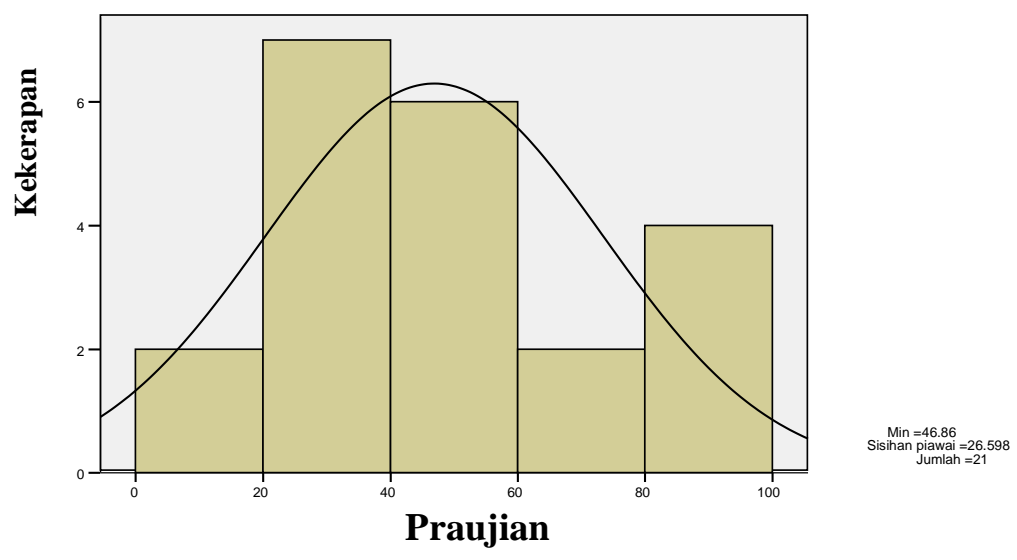

CARTA 1 Dapatan Praujian 


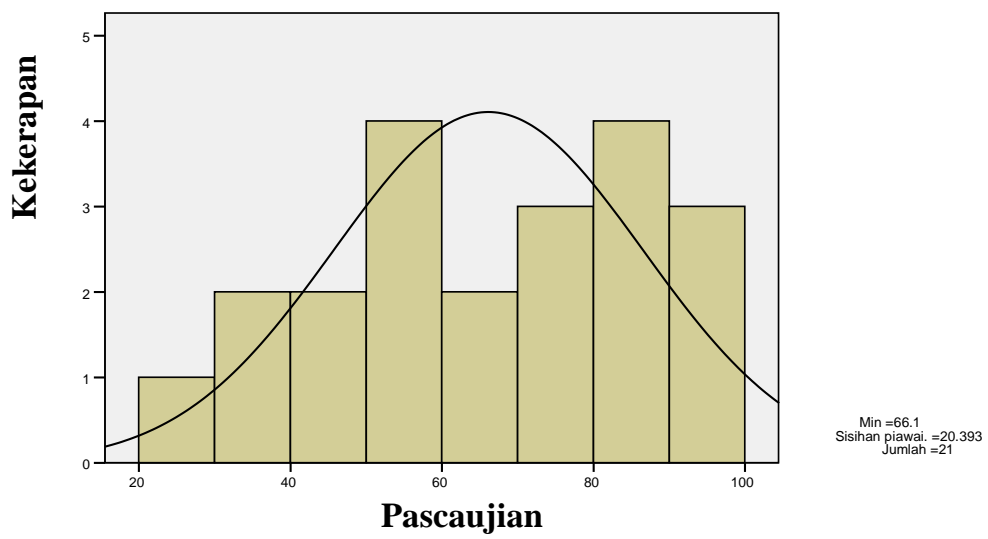

CARTA 4 Dapatan Pascaujian

Hasil dapatan kualitatif pula diperoleh daripada wawancara dan temu ramah serta pemantauan di dalam kelas semasa pengajaran dan pembelajaran berlangsung. Selain meneliti tahap pemahaman melalui respons, terdapat juga usaha mencatat data mengenai keterlibatan murid dan interaksi yang berlaku antara murid dengan murid dan murid dengan guru. Melalui penelitian ini, lima kategori yang dikumpulkan dan berkait rapat dengan kajian, iaitu:

(1) PEMAHAMAN MURID - Selain terdapatnya peningkatan pemerolehan kosa kata murid yang diperoleh melalui pra dan pascaujian, murid juga menunjukkan pemahaman meningkat terhadap arahan yang diberikan dalam kelas melalui interaksi di dalam kelas. Murid menunjukkan keupayaan mereka memahami apa yang didengar melalui respons lisan. Dari segi pergerakan, didapati murid melakukan pergerakan yang diarahkan. Pemahaman mereka juga diukur daripada komen yang diberikan. Contohnya, ada murid yang memberikan komen seperti, "Cikgu, you are too fast for the others. For me, I can understand you”. Murid juga dapat memberikan terjemahan pada ayat yang dibaca dalam EL selepas mendengar bacaan guru dalam BM. Misalnya apabila guru membaca, "Lompat, Didi lompat!", ada yang menyampuk, “Jump, Didi jump!” Respons ini menunjukkan bahawa kefahaman mereka terhadap interaksi dalam bahasa Melayu di kelas semakin meningkat.

(2) PENAMBAHAN KosA KATA - Terdapat juga penambahan kosa kata melalui interaksi antara murid dengan murid dan guru dengan murid. Pada mula pembelajaran, murid sering menjawab dengan menggunakan jumlah perkataan yang terhad atau perkataan dalam EL. Lama kelamaan, terdapat penambahan perkataan dalam ayat yang interaksilisan yang sebelum ini amat terhad. Contohnya, "Cikgu, saya tandas" yang sebelum ini diujarkan dalam EL atau, "Itu ada dua".

(3) KEBERGANTUNGAN KEPADA EL - Kebergantungan kepada EL dalam interaksi antara guru dan murid semakin berkurangan. Hal ini dapat dikesan melalui komunikasi dalam kelas. Pada mulanya semasa hari pertama, guru memberikan arahan dalam BM dan kemudiannya menterjemahkannya dalam EL. Namun, pada hari-hari selanjutnya, guru lebih banyak menggunakan BM semasa memberikan arahan dan membuat penerangan. Hal ini merupakan satu petanda yang menunjukkan bahawa murid-murid semakin terangsang untuk menggunakan BM dan kurang bergantung pada EL untuk tujuan komunikasi dalam kelas. Guru juga berpendapat bahawa mereka tidak harus selalu menterjemahkan setiap perkataan atau ayat, seperti mana yang sering dilakukan, yaknterpaksa menterjemah perkataan, ayat atau kandungan teks yang dibaca.

(4) MOTIVASI MURID - Kajian ini menunjukkan bahawa terdapat peningkatan bagi keinginan untuk melakukan tugasan atau memberikan respons dalam proses pembelajaran. Di dalam kelas bahasa juga, murid menunjukkan kerelaan mereka mengambil bahagian dan melibatkan diri secara aktif 
dalam pembelajaran. Kesungguhan ini juga menunjukkan terdapat motivasi dalam proses pembelajaran. Motivasi pula sering dikaitkan dengan pengalaman pembelajaran murid, terutama sekali dalam aspek memperlihatkan kerelaan mereka melibatkan diri dalam aktiviti dalam kelas dan sebab utama mereka bertindak demikian (Yi-Chia \& Hsin-Te, 2009). Terdapat sikap murid-murid yang berlumba-lumba membuat percubaan dalam memberikan jawapan dan apabila mendapat jawapan yang betul, mereka terangsang untuk membuat percubaan. Murid menjadi lebih responsif dengan aktiviti yang diberikan oleh guru dan tidak perlu dipanggil nama untuk menjawab setiap soalan yang dikemukakan oleh guru. Hal ini mencerminkan keberanian dan keyakinan mereka yang meningkat dalam mencuba untuk memberikan respons. Terdapat juga murid yang pendiam, akan kemudiannya bersuara untuk cuba memberikan jawapan selepas pelajaran 2 dan 3 kerana mereka berasa lebih selesa dan berkeyakinan untuk memberikan jawapan. Murid juga mengajukan pertanyaan dan mengambil bahagian yang aktif.dalam pembelajaran.

(5) BAHAN DWIBAHASA - Dua orang guru yang menjalankan pengajaran BM dengan menggunakan bahan dwibahasa ini berpendapat bahawa bahan ini mempunyai kekuatan dari segi memberikan bantuan kepada murid memahami cerita dengan menggunakan perkataan yang telah dikuasai dan digunakan di rumah. Mereka juga memberikan pendapat bahawa kesan visual yang terdapat juga dapat dalam bahan memberikan sokongan. Mereka menambah bahawa bahan yang mempunyai ilustrasi yang menarik dan warna yang ceria dapat membangkitkan minat dan menarik perhatian murid. Perkara-perkara ini membantu murid memperoleh kosa kata yang baharu sekali gus membina makna dari apa yang didengar dan dibaca. Selain itu, jika bahan ini diberi nilai tambah dengan elemen interaktif seperti dijadikannya dalam bentuk buku elektronik dengan animasi dan bunyi, bahan ini berpotensi untuk mempercepat pembelajaran. Mereka juga memberikan saranan agar aspek budaya Melayu harus diterap dan ditekankan agar murid boleh meningkatkan pengetahuan mereka terhadap budaya Melayu yang dipelajari Jalan cerita, latar belakang dan watak dapat membantu menyerap dan menerapkan aspek budaya Melayu. Genre yang digunakan juga haruslah pelbagai agar tidak membosankan murid.

\section{KESIMPULAN KAJIAN}

Kajian ini memperlihatkan cabaran dan keupayaan dalam usaha memperoleh dan meningkatkan jumlah kosa kata dan pemahaman murid-murid yang datang daripada keluarga yang bukan penutur jati. Walaupun terdapat kesedaran bahawa perbendaharaan yang mencukupi tidak menjamin pemahaman yang tinggi, kekurangan kosa kata menjejaskan kemahiran membaca secara keseluruhan (Biemiller, 2005, hal. 223-242).

Namun begitu, perancangan yang teliti dan pelbagai tahap kemahiran guru dalam proses PdP perlu dipersiap bagi memastikan agar penggunaan bahan dwibahasa ini berkesan dan dapat meningkatkan motivasi murid untuk membantu mereka dalam mempelajari BM. Dalam situasi ini, murid juga boleh menggunakan penguasaan EL mereka dalam mempelajari BM kerana mereka sebenarnya telahpun memperoleh konsep tentang sesuatu perkara dalam EL. Apabila tahap kemahiran berbahasa mereka semakin kukuh, penggantungan terhadap teks-teks begini bolehlah dikurangkan. Dengan erti kata lain, bahan ini boleh digunakan sebagai perancah bagi membina kemahiran bahasa.

Satu perkara lagi ialah kajian ini menunjukkan bahawa terdapat cara lain untuk mengajarkan BM selain daripada menggunakan teknik terjemahan. Guru mempunyai pelbagai cara dan tidak terhad dengan penggunaan kaedah terjemahan semasa mengajar. Hal ini dapat memberikan peluang bagi guru memperluas lagi kosa kata dan memperdalam pemahaman murid tersebut dengan lebih berkesan. Kaedah terjemahan dalam pengajaran dan pembelajaran didapati amat meletihkan dan kadangkala membosankan. Oleh itu, bahan dwibahasa dapat merangsang pemikiran murid dan dapat membolehkan mereka membina makna dengan menggunakan kekuatan pemahaman dan penguasaan mereka dalam bahasa Inggeris. 


\section{KAJIAN MASA HADAPAN}

Banyak usaha yang boleh dilakukan untuk memperbaiki kajian. Kajian eksperimental yang melibatkan dua kumpulan; kumpulan kawalan dan eksperimen dapat memberikan lebih banyak peluang untuk mengukur tahap keberkesanan dalam pengajaran dan pembelajaran. Selain itu, jumlah sampel boleh ditambah agar kajian menjadi lebih sahih dan boleh dipercayai serta dapat disalin tepat atau direplikat untuk meningkatkan tahap kebolehpercayaan dan kesahan kajian secara tekal. Pemantauan yang berterusan harus ditjalankan agar murid-murid dapat meningkatan kosa kata dan memperkukuhkan kemahiran bahasa yang lain, seperti kemahiran membaca dan memahami pada peringkat yang tinggi. Elemen penilaian berasaskan perlakuan atau task-based performance boleh diterapkan untuk menguji tahap pencapaian kemahiran lisan dan pemahaman. Kajian seumpama ini juga boleh diperluas ke peringkat prasekolah bagi membantu kanak-kanak memperoleh kemahiran asas BM atau dilanjutkan ke program bahasa ketiga yang ditawarkan kepada mereka yang lebih dewasa dan berminat untuk mempelajari BM.

\section{PENUTUP}

Dasar dwibahasa Singapura telah berjaya mempertingkatkan kadar literasi warga Singapura meningkat. EL sebagai bahasa pengantar telah membolehkan warga Singapura berhubung dengan dunia untuk kepentingan ekonomi. BI pula membolehkan warganya berhubung dengan warisan dan asal usul mereka serta mengukuhkan jati diri. Namun, untuk memastikan bahawa kejayaan ini terus dapat dikecapi, pendidikan BI haruslah terus dikemas kini agar perkembangan ini dapat menampung dan menangani perubahan-perubahan persekitaran bahasa yang berlaku di dalam dan luar negara. Dalam konteks Sistem Pendidikan Singapura, usaha yang tekal, gigih dan berterusan perlu dilakukan supaya dapat membantu warganya menguasai dwibahasa untuk meraih manfaat dalam bidang ekonomi dan sosial. Usaha cuba jaya dalam membuat perubahan sudah tentu dapat memberikan pengalaman pembelajaran yang amat berharga. Dalam masa yang sama, usaha meneliti kajian-kajian tentang pemerolehan bahasa harus digiatkan lagi untuk membantu pihak penggubal kurikulum dalam memperhalus dasar dengan berlandaskan maklumat yang terkini. Di samping itu, sebarang semakan bahasa haruslah melibatkan masyarakat dari pelbagai lapisan agar dapat menjayakan dasar ini dengan penuh pemahaman dan komitmen serta kebertanggungjawabannya.

\section{RUJUKAN}

Au Yong, J. (2009). Bilingual policy was most difficult: Minister Mentor, The Straits Times, 6 Nov 2009, Home Page B6.

Biemiller, A. (2005). Size and sequence in vocabulary development: Implications for choosing words for primary grade vocabulary instruction. In A. Hiebert. \& M. Kamil, (Eds.), Teaching and Learning Vocabulary: Bringing Research to Practice

Brozo, W. G., (1999). Readers, Teachers, Learners: Expanding Literacy Across the Content Areas. New Jersey: Prentice-Hill Inc.

Cummins, J. (1980). The Cross-lingual Dimension of Language Proficiency: Implications for Bilingual Education and the Optimal Age Issue. TESOL Quartely, Vol 14, hal 175 - 187.

Dixon, L. Q. (2005). The Bilingual Policy in Singapore: Implications for Second Language Acquisition, Proceedings of the 4th International Symposium on Bilingualism, MA: Casdilla Press.

Driessen, C., Westhoff, G., Haenen, J., \& Brekelmans, M. (2008). A qualitative analysis of language learning tasks: The design of a tool. Journal of Curriculum Studies, 40(6), 803-820.

Durgunoğlu, A.Y., Nagy, W.E., \& Hancin-Bhatt, B.J. (1993). Cross language transfer of phonological awareness. Journal of Educational Psychology.

Edwards, V., Monaghan, F., \& Knight, J. (2000). Books, Pictures and Conversations: Using Bilingual Multimedia Storybooks to Develop Language Awareness, Language Awareness, 9(3), 135-146,

Kementerian Pendidikan (2005) Laporan Jawatankuasa Semakan Kurikulum dan Pedagogi Bahasa Melayu. Singapura. 
Kementerian Pendidikan (2010) Laporan Jawatankuasa Semakan Kurikulum dan Pedagogi Bahasa Melayu. Singapura.

Lee, K. Y., (2012) My Lifelong Challenge: Singapore’s Bilingual Journey. Singapore Press Holding.

Lim T. B. \& Commission of Inquiry into Education, (1964). Commission of Inquiry into Education Singapore Final Report. Singapore Government Printers.

Krashen, Stephen D. (1981) Principles and Practice in Second Language Acquisition. English Language Teaching series. London: Prentice-Hall International (UK) Ltd. 202 pages.

Mukhlis, A.B. \& Pang., (2015) Learning to be Biliterate in English and Malay Using Dual Language Books, NIE Research Brief Series No. 15-013. Singapore: National Institute of Education.

Marshall, C. \& Rossman, G.B., (1999) Designing Qualitative Research 2nd edition. CA: Sage Publication. Inc.

Neugebauer, S., \& Currie-Rubin, R. (2009). Read-Alouds in Calca, Peru: A Bilingual Indigenous Context. The Reading Teacher.

Senechal, M. \& LeFevre, J. (2002). Parental involvement in the development of child's reading skill: A five Year Longitudinal Study. Child development, March/April 2002, volume 73, Number 2, page 445-460.

Sneddon, R., (2000). Magda and Albana: Learning to read with dual language books. Language and Education.

Vaish, Viniti \& Subhan, Aidil, (2014). Translanguaging in a reading class. International Journal of Multilingualism. 12. 1-20. 10.1080/14790718.2014.948447.

Yi-Chia, C. \& Hsin-Te, Yeh, (2009). From Concept of Motivation to its Application in Instructional Design: Reconsidering Motivation from an Instructional Design Perspective. British Journal of Educational Technology, 40(4), 597-605. 